\title{
Morphological Approach to the Study of the Dynamics of Changes in the Fibrous Structures of the Dermis in Dermotension
}

\author{
Lyubov A. Kopteva ${ }^{1}$, Ekaterina S. Mishina ${ }^{1 *}$, Maria A. Zatolokina ${ }^{1}$, Maxim V. Mnichovich ${ }^{2}$, \\ Elena S. Chernomortseva ${ }^{1}$ \\ ${ }^{1}$ Kursk State Medical University, Kursk, Russia \\ ${ }^{2}$ Research Institute of Human Morphology, Moscow, Russia
}

\begin{abstract}
Background: The method of dermotension is successfully used in surgical practice to close extensive defects or as a result of treating fractures using the Ilizarov apparatus. However, to obtain the desired result, surgeons often neglect the condition of the skin flap itself. In this regard, the purpose of our study was to study the dynamics of changes in fibrous structures in the dermis of the skin during dermotension.

Methods and Results: The material for the 14-day study was a skin flap of Wistar rats obtained after distraction with the Ilizarov apparatus. Analyzing the morphological picture of the state of the dermis after the study, we found a decrease in the thickness of both the epidermis and the dermis by 2.3 and 3.3 times, respectively. A decrease in the density of collagen structures of both types I and III was also noted.

Conclusion: The results obtained indicate the restructuring, first of all, of the fibrous component of the dermis, which consists in reparative-restorative processes, which must be taken into account when choosing the rate and duration of dermotension. International Journal of Biomedicine. 2021;11(1):96-98.)
\end{abstract}

Key Words: dermotension • fibrous skeleton • Ilizarov apparatus $\bullet$ skin $\bullet$ adaptive rearrangements

For citation: Kopteva LA, Mishina ES, Zatolokina MA, Mnichovich MV, Chernomortseva ES. Morphological Approach to the Study of the Dynamics of Changes in the Fibrous Structures of the Dermis in Dermotension. International Journal of Biomedicine. 2021;11(1):96-98. doi:10.21103/Article11(1)_OA17

\section{Introduction}

As a material for alloplasty, skin is widely used in the treatment of various surgical pathologies. In such cases, the most widespread methods of dermotension are the Ilizarov apparatus or balloon methods. ${ }^{(1-5)}$ The literature available to us contains mainly the results observed in clinical practice, and there are no data on morphological changes as a result of stretching. ${ }^{(6-9)}$ In this regard, the aim of the work was to study the adaptive rearrangement of the fibrous skeleton of the rat dermis under conditions of dermotension.

*Corresponding author: Ekaterina S. Mishina, PhD Department of Histology, Embryology, and Cytology. Kursk State Medical University. Kursk, Russia. E-mail: katusha100390@,list.ru

\section{Materials and Methods}

The material for this study was the skin of the anterior surface of the tibia of 30 laboratory animals, male Wistar rats, which 5 days after flexion osteoclasia of the tibia underwent tibia lengthening using the Ilizarov apparatus at a daily rate of $0.5 \mathrm{~mm}$ in 4 doses. The animals were removed from the experiment after 14 days of distraction. The skin of intact animals was examined as a control.

The experiments were performed in accordance with the norms for the humane treatment of animals, which are regulated by the International Guidelines of the Association for the Assessment and Accreditation of Laboratory Animal Care, and approved by the Regional Ethics Committee of Kursk State Medical University (Protocol No. 4 dated June 10, 2019). 
A fragment of skin, $1 \times 1 \mathrm{~cm}$ in size, after fixation, was studied using light-optical microscopy (staining by the Mallory method) and a scanning electron microscopy (SEM). To determine the types of collagen, the preparations were stained with Sirius Red, and then examined in polarized light using an Altami Polar 2 polarizing microscope, at a magnification of $\times 100$.

Statistical analysis was performed using the statistical software Microsoft Excel-2003. The normality of distribution of continuous variables was tested by the Kolmogorov-Smirnov test with the Lilliefors correction and Shapiro-Wilk test. For descriptive analysis, results are presented as mean \pm standard deviation (SD). The Mann-Whitney U-test was used to compare the differences between the two independent groups. A probability value of $P \leq 0.05$ was considered statistically significant.

\section{Results}

The middle layer was stretched parallel to the direction of the tensile forces. Figure 1 presents the orientation of collagen and elastic fibers. In the papillary layer, there are mostly thin, branched collagen fibers that form delicate reticular structures. In the mesh layer, the fibers have a larger diameter. Along with large bundles of fibers, thinner reticular structures and a microfibrillar component were found around fibroblasts. At the border of the reticular layer and the hypodermis, destruction of the fibrous skeleton was observed. At the same time, active neocollagenesis was not observed. A significant number of microvessels, mainly of the capillary type, were observed in the papillary and outer part of the reticular dermis.

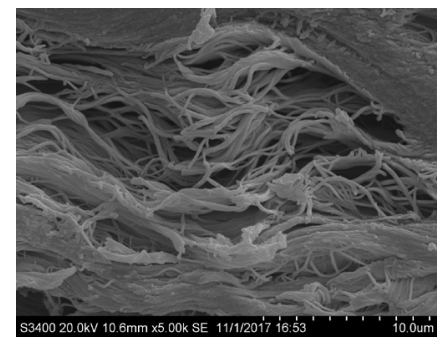

A

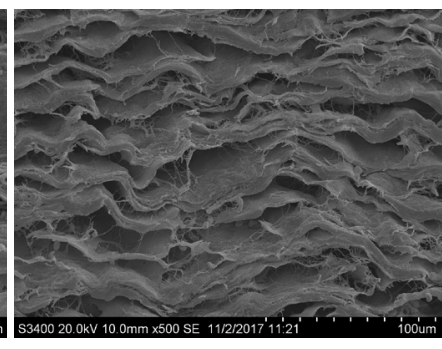

$B$
Fig. 1. Micrograph of the skin after dermotension. A Subepidermal layer of the dermis, SEM $\times 5000$; B - Fibrous structures of the dermis with predominant anisotropy, SEM $\times 500$

When studying the cellular component, we determined the stimulating effect of mechanical action on the activation and proliferative activity of fibroblastic diferon. By the end of the period of distraction in the dermis, there was a significant increase in the number and density of all types of cells found in it, with the exception of fibrocytes. At the same time, under the conditions created during the period of distraction, both pronounced heteromorphism of the cells of the leading fibroblastic population and changes in the ratio of macrophages and mast cells were noted. An active macrophage reaction was observed in the papillary layer, less pronounced in the reticular layer of the skin. Mast cell accumulations were observed near microvessels (Table 1).

Table 1.

Quantitative characteristics of the structural components of the skin

\begin{tabular}{|l|c|c|c|}
\hline \multicolumn{1}{|c|}{ Parameters } & Control & Dermotension & $P$-value \\
\hline Thickness of epidermis & $30.5 \pm 0.3 \mu \mathrm{m}$ & $12.90 \pm 0.10 \mu \mathrm{m}$ & $\leq 0.05$ \\
\hline Thickness of dermis & $2.47 \pm 0.04 \mathrm{~mm}$ & $0.73 \pm 0.11 \mathrm{~mm}$ & $\leq 0.05$ \\
\hline \multicolumn{4}{|c|}{ Numerical density of cells per $1 \mathrm{~mm}^{2}$ of the dermis } \\
\hline Fibrocytes & $37.6 \pm 1.2$ & $19.5 \pm 0.9$ & $\leq 0.05$ \\
\hline Fibroblasts & $15.3 \pm 0.8$ & $41.7 \pm 1.1$ & $\leq 0.05$ \\
\hline Macrophages & $6.70 \pm 0.21$ & $33.0 \pm 1.9$ & $\leq 0.05$ \\
\hline Mast cells & $7.03 \pm 0.18$ & $10.23 \pm 0.2$ & $\leq 0.05$ \\
\hline
\end{tabular}

When studying photomicrographs of the skin of control animals after polarizing microscopy, we observed a large number of collagen fibers, predominantly type $\mathrm{I}$, in the dermis (Figure 2A) and a fairly, uniformly high density of fibrous structures (Table 2).

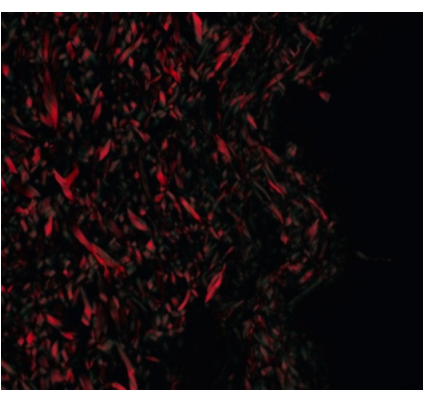

$A$

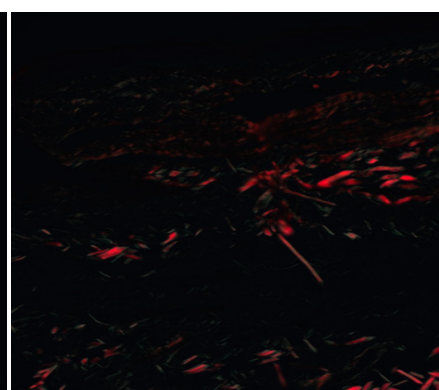

$B$
Fig. 2. Micrograph of the dermis of rats. Polarizing microscopy. Sirius Red coloring, $\times 100 ; A-$ in the control group. B - with distraction.

Table 2.

Distribution of collagen types in the dermis of the skin

\begin{tabular}{|l|c|c|c|c|}
\hline \multicolumn{1}{|c|}{ Group } & $\begin{array}{c}\text { Field area in } \\
1000 \text { pixels }\end{array}$ & $\begin{array}{c}\text { Red PD } \\
\text { (TIC) }\end{array}$ & $\begin{array}{c}\text { Green PD } \\
\text { (TIIIC) }\end{array}$ & $\begin{array}{c}\text { Collagen ratio } \\
\text { (I/III) }\end{array}$ \\
\hline Control & $235.2 \pm 1.7$ & $25.1 \pm 1.1$ & $7.6 \pm 1.1$ & $3.3 \pm 0.32$ \\
\hline Dermotension & $348.2 \pm 2.1^{*}$ & $8.62 \pm 0.76^{*}$ & $11.9 \pm 1.3$ & $0.72 \pm 0.1^{*}$ \\
\hline$P$-value & $\leq 0.05$ & $\leq 0.05$ & $>0.05$ & $\leq 0.05$ \\
\hline
\end{tabular}

PD - pixel density; TIC-type I collagen; TIIIC- type III collagen

In the study of sections stained with hematoxylin and eosin in the experimental animals with skin distraction, the density of collagen in the dermis had decreased sharply. When staining with Sirius Red in the dermis, we noted a sharp decrease in the density of collagen fibers (Figure 2B). Moreover, the main decrease in density occurred in the surface 
layers of the dermis. When studying the same skin fragment in polarized light, we noted a very weak red glow and a slight green glow, which indicates a decrease in the density of type I collagen by 2.9 times and an increase in type III collagen by 1.5 times.

In conclusion, the revealed structural features of the dermis and analysis of reactive changes in various cell populations can serve as criteria for assessing the phasing of reparative processes developing under the created conditions, and can be taken into account when developing the staging and rate of stretching to justify their introduction into clinical practice.

\section{Competing interests}

The authors declare that they have no competing interests.

\section{References}

1. Martel II, Grebenyuk LA, Dolganova TI. [Elimination of an extensive femoral soft-tissue defect using dermotension according to Ilizarov technology]. ORTHOPAEDIC GENIUS. 2016;(4):109-113. [Article in Russian].

2. Bogosyan RA. [Expander dermotension - a new method for surgical filling of skin defects. Modern Technologies in Medicine]. 2011;2:31-34. [Article in Russian].

3. Filippova OV, Baindurashvili AG, Afonichev KA,
Vashetko RV. [Surgical treatment of children with scars on the lower leg and in the area of Achilles tendon using expander dermatension]. Traumatology and Orthopaedics of Russia. 2015; 1 (75): 74-82. [Article in Russian].

4. Grebenyuk LA, Kobyzev AE, Grebenyuk EB, Ivliev DS. [The technique of determining plastic reserves of the skin in patients with orthopedic pathology]. Medical Science and Education of Ural. 2013; 14(4): 11-17. [Article in Russian].

5. Mishina ES, Omelyanenko NP, Kovalev AV, Volkov AV, Smorchkov MM. [Structural dynamics of the skin when modeling dermotension]. Annals of Plastic, Reconstructive, and Aesthetic Surgery. 2018;4:10. [Article in Russian].

6. Dąbrowska AK, Spano F, Derler S, Adlhart C, Spencer ND, Rossi RM. The relationship between skin function, barrier properties, and body-dependent factors. Skin Res Technol. 2018 May;24(2):165-174. doi: 10.1111/srt.12424.

7. Maiti R, Gerhardt LC, Lee ZS, Byers RA, Woods D, SanzHerrera JA, Franklin SE, Lewis R, Matcher SJ, Carré MJ. In vivo measurement of skin surface strain and sub-surface layer deformation induced by natural tissue stretching. J Mech Behav Biomed Mater. 2016 Sep;62:556-569. doi: 10.1016/j. jmbbm.2016.05.035.

8. Svoboda M, Bílková Z, Muthný T. Could tight junctions regulate the barrier function of the aged skin? J Dermatol Sci. 2016 Mar;81(3):147-52. doi: 10.1016/j.jdermsci.2015.11.009. 9. Dibirov M, Gadzhimuradov R, Koreiba K, Minabutdinov A, Biomedical Technologies in the Treatment of Skin and Soft Tissue. Defects in Patients with Diabetic Foot Syndrome. International Journal of Biomedicine. 2016;6(1):41-45. 